\title{
Thermodynamic Study of Oxygen in Liquid Elements of Group Ib to VIb
}

\author{
By Shinya Otsuka* and Zensaku Kozuka*
}

\begin{abstract}
The activity coefficient of oxygen in liquid cadmium at $773 \mathrm{~K}$ was measured by the electrochemical technique employing a solid electrolyte. Two empirical correlations of the thermodynamic values for oxygen dissolution between the elements of group Ib to VIb have been established in this paper on the basis of the data previously obtained by a modified coulometric titration method. By combining the measured value at $773 \mathrm{~K}$ with one of the correlations, the standard Gibbs energy of solution of oxygen in liquid cadmium for $1 / 2 \mathrm{O}_{2}(101325 \mathrm{~Pa}) \rightarrow \underline{\mathrm{O}}(1 \mathrm{~mol} \%)$ has been determined as a function of temperature as follows:

$$
\Delta G^{\circ} \text { (in Cd) } / \mathbf{J} \cdot \mathrm{mol}^{-1}=-142540+9.4(T / \mathrm{K}) \text {. }
$$

The standard Gibbs energy of formation of $\mathrm{CdO}$ in the range of 742 to $831 \mathrm{~K}$ was experimentally determined using a similar electrochemical cell. The result is $\Delta G^{\circ}(\mathrm{CdO}) / \mathrm{J} \cdot \mathrm{mol}^{-1}=-261510+106.9(T / \mathrm{K})$.

The saturation solubility of oxygen in liquid cadmium calculated from the combination of these two results is

$$
C_{s}(\mathrm{in} \mathrm{Cd}) / \mathrm{mol} \%=\exp \{11.73-14309 /(T / \mathrm{K})\} \text {. }
$$

Based on the foregoing two correlations, the standard Gibbs energies of solution of oxygen in liquid zinc, aluminium, silicon, arsenic and selenium have been evaluated as follows:

$$
\begin{aligned}
& \left.\Delta G^{\circ} \text { (in } \mathrm{Zn}\right) / \mathrm{J} \cdot \mathrm{mol}^{-1}=-213400+19(T / \mathrm{K}), \\
& \left.\Delta G^{\circ} \text { (in } \mathrm{Al}\right) / \mathbf{J} \cdot \mathrm{mol}^{-1}=-364800+41(T / \mathrm{K}), \\
& \left.\Delta G^{\circ} \text { (in } \mathrm{Si}\right) / \mathbf{J} \cdot \mathrm{mol}^{-1}=-290700+37(T / \mathrm{K}), \\
& \left.\Delta G^{\circ} \text { (in } \mathrm{As}\right) / \mathbf{J} \cdot \mathrm{mol}^{-1}=-119600+16(T / \mathrm{K}), \\
& \Delta G^{\circ} \text { (in Se) } / \mathbf{J} \cdot \mathrm{mol}^{-1}=-43800+37(T / \mathrm{K}) .
\end{aligned}
$$
\end{abstract}

(Received March 13, 1981)

\section{Introduction}

There has been growing interest in finding a few correlations of the thermodynamic values of oxygen dissolved in liquid elements between the various groups ${ }^{(1) \sim(5)}$. This research program will further our understanding of the thermodynamic behavior of oxygen and make it possible to predict the corresponding thermodynamic values for elements where the data are not available. Recently, we have improved a modified coulometric titration method described in previous papers ${ }^{(6)(7)}$ and published the highly precise values for the standard Gibbs energy of dilute solution of oxygen in various liquid elements, i.e., $\mathrm{Cu}, \mathrm{Ag}^{(8)}$ (Group Ib), In, $\mathrm{Tl}^{(9)(10)}$ (Group IIIb), Ge, $\mathrm{Sn}^{(11)}, \mathrm{Pb}^{(10)}$ (Group $\mathrm{IVb}$ ), and $\mathrm{Sb}^{(10)}$ and $\mathrm{Bi}^{(11)}$ (Group $\mathrm{Vb}$ ). Two

* Department of Metallurgical Engineering, Feculty of Engineering, Osaka University, Suita 565, Japan. empirical correlations, based on these precise data, have been represented in the present paper. Our previous results for liquid $\mathrm{Te}$ (Group VIb) $^{(5)}$, obtained by a conventional coulometric titration method, have been found to be consistent with these correlations, because these are essentially the same correlations as discussed previously ${ }^{(5)(8)}$.

In order to be accepted as fundamental relationships for elements of group $\mathrm{Ib}$ to $\mathrm{VIb}$, the foregoing correlations, however, have to be tested for the elements of group IIb. Since the reliable data for group IIb were scarce indeed, it was decided in this study to measure the activity coefficient of oxygen dissolved in liquid $\mathrm{Cd}$. A series of our studies have permitted to predict the thermodynamic behavior of oxygen dissolved in liquid $\mathrm{Zn}(\mathrm{IIb}), \mathrm{Al}(\mathrm{III} b)$, $\mathrm{Si}(\mathrm{IVb}), \mathrm{As}(\mathrm{Vb})$ and $\mathrm{Se}(\mathrm{VIb})$, where the data are not available, though very important for pyrometallurgical processes. The standard Gibbs energy of formation of cadmium oxide has also been determined as a function of 
temperature by using a conventional electrochemical technique. Further, the saturation solubilities of oxygen in various liquid elements have been calculated from the measured or predicted values for the standard Gibbs energy of solution of oxygen and the standard Gibbs energy of formation of the corresponding oxide.

\section{Experimental}

\section{Oxygen activity in liquid cadmium}

In order to determine the oxygen activity in liquid cadmium, an electrochemical cell was investigated of the type:

$$
\text { O in liquid } \underset{\mathrm{P}_{\mathrm{O}_{2}}^{\prime}}{\mathrm{Cd} / \mathrm{ZrO}_{2}\left(+\mathrm{Y}_{2} \mathrm{O}_{3}\right) / \mathrm{Air}, \mathrm{Pt}}
$$

where $P_{\mathrm{O}_{2}}^{\prime}$ and $P_{\mathrm{O}_{2}}^{\prime \prime}$ were the oxygen partial pressures at the liquid cadmium-electrolyte interface and in the reference gas, respectively. In view of the relatively high vapor pressure of cadmium, the experiments for the oxygen activity were performed only at $773 \mathrm{~K}$. This cell assembly, shown in Fig. 1, is similar to

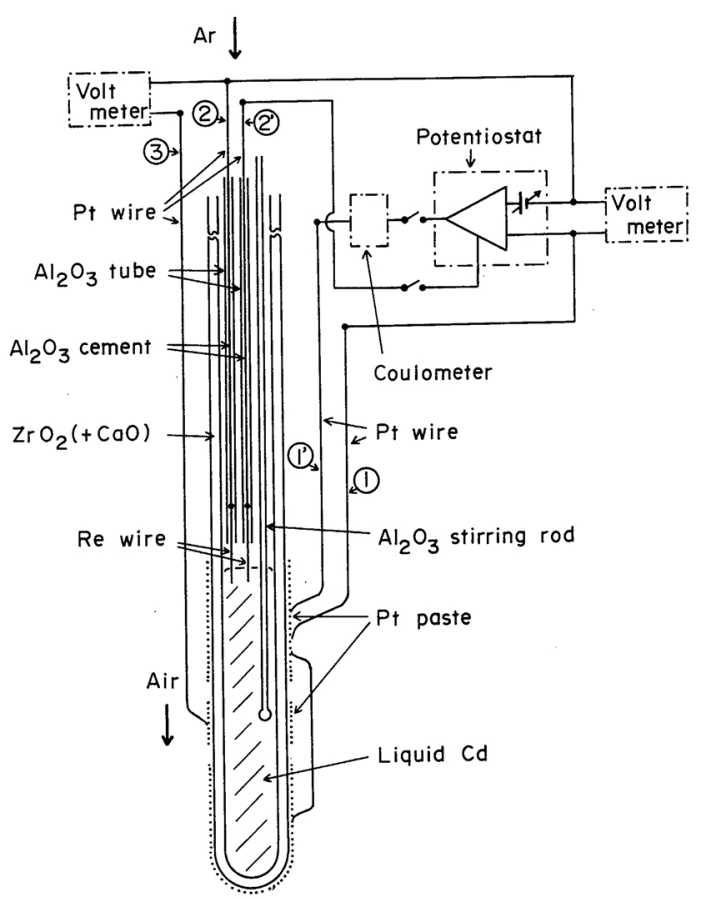

Fig. 1 Electrochemical cell (I) for the measurements of oxygen activity in liquid cadmium. that used for liquid tellurium ${ }^{(5)}$. The experimental technique used in this study is essentially the same as the modified coulometric titration method described in previous papers ${ }^{(7) \sim(11)}$.

A $\mathrm{ZrO}_{2}\left(+14\right.$ mass $\left.\% \quad \mathrm{Y}_{2} \mathrm{O}_{3}\right)$ solid electrolyte tube, closed at one end, was supplied by Nippon Kagaku Togyo Co., Ltd. in the form of $8 \mathrm{~mm}$ o.d., $5 \mathrm{~mm}$ i.d., and $300 \mathrm{~mm}$ length. About $10 \mathrm{~g}$ of granular cadmium (99.999 mass \% purity) were loaded into the electrolyte tube, in quantity corresponding to $65 \sim 70 \mathrm{~mm}$ height. Rhenium wires $(0.25 \mathrm{~mm})$ connected with platinum wires were used as the lead wires for liquid cadmium. These connections were taken in a uniform temperature zone. Platinum paste ( $325 \mathrm{mesh})$ was painted on the electrolyte in three parts. The platinum electrode, painted at the center over a length of $10 \mathrm{~mm}$, was used as the reference electrode for the open-circuit emf measurements. Two platinum electrodes, painted over a length of $25 \mathrm{~mm}$ respectively, used for the pump-out or pump-in experiments, were $5 \mathrm{~mm}$ away from the foregoing electrode.

Liquid cadmium was first deoxidized by passing a current through the cell (I), otherwise CdO suspended in the melt would lead to serious errors in the data. A current was then passed in the opposite direction by applying a voltage to the cell, and the initial open-circuit emf, $E_{1}(r)$ between wires (2) and (3) was approximately controlled to a preselected value. After the emf was monitored for 0.6 or more ks without stirring the melt, the liquid cadmium was stirred again. The alumina stirring rod was then pulled out of the melt, the initial emf, $E_{1}(r)$ recorded, and a potentiostatic pump-out experiments started by applying a voltage between wires (1) and (2)' so that the emf between wires (1) and (2) was set at a preselected value of $E_{2}(m)$.

The initial open-circuit emf, $E_{1}(r)$ of the cell(I) is related to the initial oxygen concentration in the liquid cadmium, $C_{1}$ by eq. $(1)^{(12)}$ :

$$
\begin{aligned}
E_{1}(r) & =\frac{R T}{4 F} \ln \frac{P_{\mathrm{O}_{2}}^{\prime \prime}}{P_{\mathrm{O}_{2}}^{\prime}}=\frac{R T}{2 F} \ln \frac{\sqrt{0.21}}{a_{\underline{\mathrm{O}}}} \\
& =\frac{R T}{2 F} \ln \left(\frac{\sqrt{0.21}}{\gamma_{\underline{\mathrm{O}}} C_{1}} \times 100\right)
\end{aligned}
$$


where $R$ is the gas constant, $T$, the experimental temperature $(\mathrm{K}), F$, the Faraday constant, $a_{\mathrm{O}}$ the activity of oxygen in liquid cadmium with respect to the standard state of the $P_{\mathrm{O}_{2}}^{*}=$ $101325 \mathrm{~Pa}$ pure oxygen gas, $\left\{a_{\mathrm{Q}}=\left(P_{\mathrm{O}_{2}} / P_{\mathrm{O}_{2}}^{*}\right)^{1 / 2}=\right.$ $\left.\gamma_{\underline{Q}} N_{1}=\left(\gamma_{\underline{Q}} C_{1} / 100\right)\right\}, \gamma_{\underline{Q}}$, the activity coefficient of oxygen in the liquid cadmium, and $N_{1}$ and $C_{1}$, the initial oxygen concentration in the liquid cadmium in mol fraction and $\mathrm{mol} \%$ respectively.

If the oxygen in liquid cadmium obeys Henry's law, an initial oxygen concentration in liquid cadmium, $C_{1}$ can be related to the total quantity of electrical charge due to ionic current passing through cell (I) by eq. (2) ${ }^{(8)}$ :

$$
C_{1}=100 y\left\{(y+1)+(y-1) \exp \left(\frac{-2 \Delta E F}{R T}\right)\right\}^{-1} \text {, }
$$

where $y=\left(Q_{\text {ion }} / 2 F\right) \times\left(M_{m} / W_{m}\right), \Delta E=E_{2}(m)-$ $E_{1}(r)$, and $Q_{\text {ion }}$ (coulomb), the total quantity of electrical charge due to ionic current, and $M_{m}$ and $W_{m}$, the molar mass and weight of liquid cadmium respectively. The present experiments have been carried out under the condition of $\Delta E=500 \mathrm{mV}$. Further, the $C_{1}$ values are very small so that $y=0$ inside the brackets $^{(11)}$. Hence, an initial oxygen concentration in the liquid cadmium, $C_{1}$ can be calculated in this study, according to

$$
C_{1}=100 \times \frac{M_{m}}{W_{m}} \times \frac{Q_{\text {ion }}}{2 F}
$$

which is directly derived without the assumption of Henry's law. Thus, the activity coefficient of oxygen in liquid cadmium, $\gamma_{\underline{O}}$ was calculated according to eq. (2) from the measured $C_{1}$ value for $E_{1}(r)$, and further the standard Gibbs energy of solution of oxygen in liquid cadmium, $\Delta G^{\circ}$ (in $\mathrm{Cd}$ ) for $1 / 2 \mathrm{O}_{2}$ $(101325 \mathrm{~Pa}) \rightarrow \underline{\mathrm{O}}(1 \mathrm{~mol} \%)$, was determined by:

$$
\Delta G^{\circ}(\text { in } \mathrm{Cd})=R T \ln \left(\gamma_{\mathrm{o}} / 100\right),
$$

where the reference state for dissolved oxygen is an infinitely dilute solution.

\section{Standard Gibbs energy of formation of CdO}

Using the same zirconia tube as in the cell (I), an electrochemical cell (II) was con- structed $^{(13)}$ :

$$
\mathrm{Cd}-\mathrm{CdO} / \mathrm{ZrO}_{2}\left(+\mathrm{Y}_{2} \mathrm{O}_{3}\right) / \text { Air, Pt. }
$$

The platinum paste was painted over a length of $30 \mathrm{~mm}$ from the bottom of the electrolyte. Cadmium oxide, prepared by heating granular cadmium ( 99.999 mass \%) in air at $650 \sim 750 \mathrm{~K}$, was mixed with the granular cadmium in a 1: 15 mass ratio, and then loaded into the electrolyte tube, in quantity corresponding to about $30 \mathrm{~mm}$ height.

The equilibrium oxygen partial pressure over this mixture, $P_{\mathrm{O}_{2}}(\mathrm{Cd}-\mathrm{CdO})$, is calculated from the open-circuit emf, $E$ (II) of cell(II) by using eq. (1). When the saturation solubility of oxygen in liquid cadmium is relatively small so that the activity of cadmium can be approximated to be unity, the standard Gibbs energy of formation of cadmium oxide, $\Delta G^{\circ}$ $(\mathrm{CdO})$, for the following reaction is related to $P_{\mathrm{O}_{2}}(\mathrm{Cd}-\mathrm{CdO})$ and $E(\mathrm{II})$, respectively, by:

$$
\begin{aligned}
& \mathrm{Cd}+1 / 2 \mathrm{O}_{2} \\
& \begin{aligned}
\Delta G^{\circ}(\mathrm{CdO}) & =R T \ln \sqrt{P_{\mathrm{O}_{2}}(\mathrm{Cd}-\mathrm{CdO})} \\
& =-2 E(\mathrm{II}) F+R T \ln \sqrt{0.21} .
\end{aligned}
\end{aligned}
$$

By combining eqs. (4) and (5), the saturation solubility of oxygen in liquid cadmium, $C_{s}$ in $\mathrm{mol} \%$, can be calculated using the following equation:

$$
\begin{aligned}
C_{s}(\text { in } \mathrm{Cd}) & =P_{\mathrm{O}_{2}}^{1 / 2}(\mathrm{Cd}-\mathrm{CdO}) \exp \left\{\frac{-\Delta G^{\circ}(\text { in } \mathrm{Cd})}{R T}\right\} \\
& =\exp \left\{\frac{\Delta G^{\circ}(\mathrm{CdO})-\Delta G^{\circ}(\text { in } \mathrm{Cd})}{R T}\right\} \cdot(6)
\end{aligned}
$$

\section{Experimental Results}

\section{Oxygen activity in liquid cadmium}

Typical decay curves of electric current with time are shown in Fig. 2 for various initial emf's. Since the nearly steady current contributed by the electronic component, $I_{e}$, was obtained in 1.8 or more ks, the ionic current, $I_{\text {ion }}$ passing through the cell was calculated by subtracting this nearly steady value at 1.8 or $2.4 \mathrm{ks}$ from the measured current at earlier times. The initial oxygen concentration in liquid cadmium, $C_{1}$, calculated from the total quantity of electrical charge due to the $I_{\text {ion }}$, 


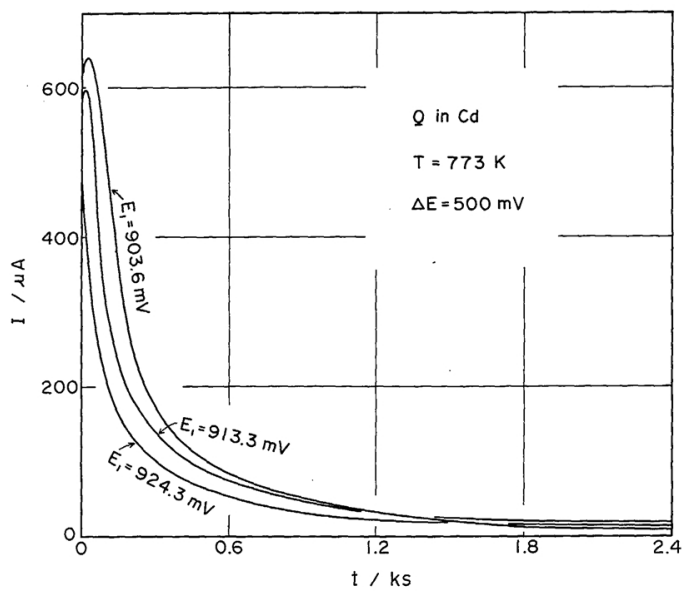

Fig. 2 Change of electric current with time for various initial emf, $E_{1}(r)$.

is plotted in Fig. 3 against the initial emf, $E_{1}(r)$. The measured values of $C_{1}$ for relatively large values of $E_{1}(r)$ are found in Fig. 3 to exhibit somewhat negative deviations from Henry's law. Since a decrease in the initial emf with time was observed in this region, the negative deviations were attributable to the error due to electronic short-circuiting and the resultant oxygen transfer through the electrolyte from the reference electrode to the melt. Hence, the activity coefficient of oxygen, $\gamma_{0}$ in liquid cadmium at $773 \mathrm{~K}$, was calculated from the $C_{1}$ value for $E_{1}(r)$ lower than $911 \mathrm{mV}$. By applying the least-squares analysis to these

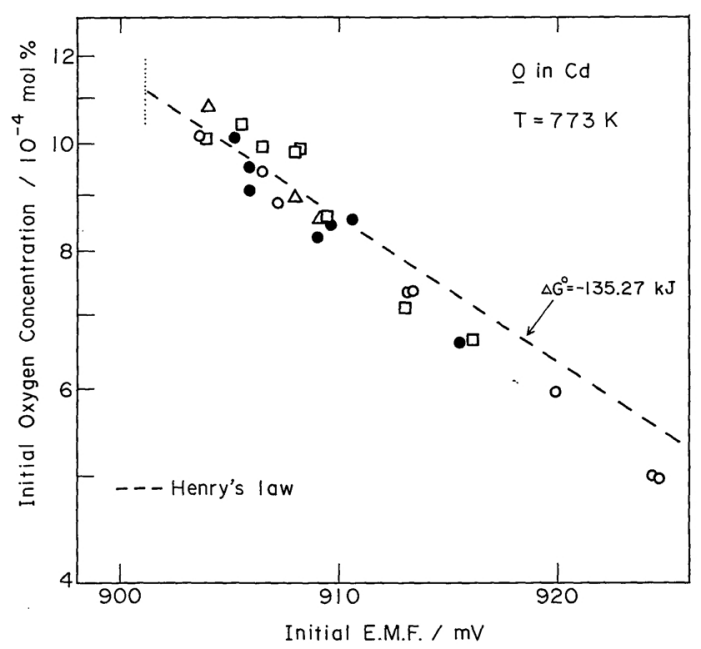

Fig. 3 Initial oxygen concentration in liquid cadmium plotted against initial emf, $E_{1}(r)$. results, the standard Gibbs energy of solution of oxygen in liquid cadmium, $\Delta G^{\circ}$ for $1 / 2$ $\mathrm{O}_{2} \quad(101325 \mathrm{~Pa}) \rightarrow \underline{\mathrm{O}}(1 \mathrm{~mol} \%)$ was calculated to be

$\Delta G^{\circ}$ (in Cd) at $773 \mathrm{~K} / \mathrm{kJ} \cdot \mathrm{mol}^{-1}=-135.27$. (7)

\section{Standard Gibbs energy of formation of CdO}

Observed emf values of cell(II) are shown by circles and triangles in Fig. 4, together with those calculated from the compilations of Barin et al. (14)(15) Highly reproducible values within $\pm 1.5 \mathrm{mV}$ were obtained in the range of 742 to $831 \mathrm{~K}$. Emf response to changes in temperature was relatively rapid and a steady value independent of the stirring was obtained in 1.8 or more ks. By the least-squares analysis, the values of the emf of cell(II) were expressed as follows:

$$
E(\mathrm{II}) / \mathrm{mV}=1355.2-0.5875(T / \mathrm{K}) .
$$

Although the present results were somewhat smaller than those calculated from the compilations of Barin et al., the slopes were in good agreement.

The saturation solubility of oxygen in liquid cadmium is very small, as clear from Fig. 3. Therefore, the standard Gibbs energy of formation of $\mathrm{CdO}$ can be calculated from eqs. (5) and (8) as follows:

$$
\Delta G^{\circ}(\mathrm{CdO}) / \mathrm{J} \cdot \mathrm{mol}^{-1}=-261510+106.9(T / \mathrm{K}) .
$$

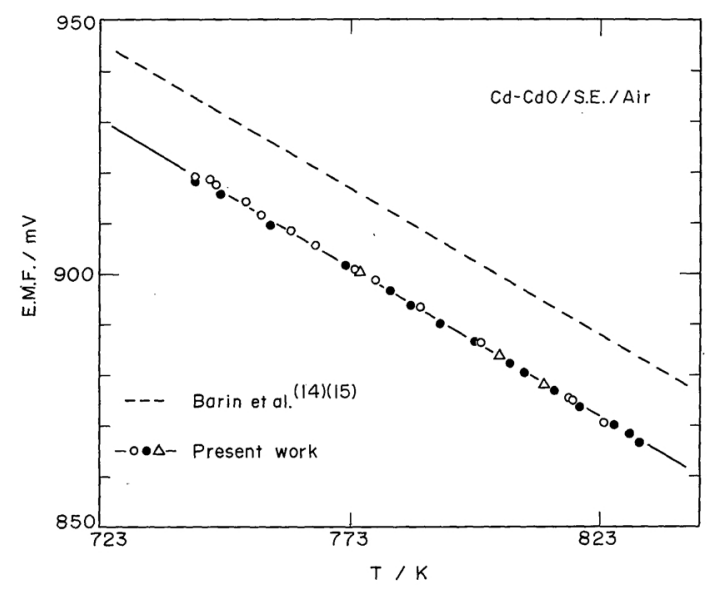

Fig. 4 Temperature dependence of the emf of the cell (II); $\mathrm{Cd}-\mathrm{CdO} / \mathrm{ZrO}_{2}\left(+\mathrm{Y}_{2} \mathrm{O}_{3}\right) / \mathrm{Air}$, Pt. 


\section{Oxygen released from solid electrolyte}

On pumping-out oxygen from liquid elements, a redistribution of oxygen potential in a solid electrolyte is accompanied with the change of the concentration of a vacant oxygen ion site, $V_{\ddot{0}}$. Since this leads to the release of oxygen from the electrolyte ${ }^{(16)}$, strictly speaking, the $C_{1}$ value, calculated from the measured $Q_{\text {ion }}$ value according to eq. (3), includes the error due to oxygen released from the solid electrolyte. Therefore, this value, defined as an apparent one, $C_{1}$ (app.), may be distinguished from the corresponding true

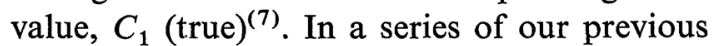
investigations, the amount of oxygen released from the electrolyte has been estimated from the $C_{1}$ (app.) value for very low oxygen concentrations in liquid elements and then subtracted in order to evaluate the true initial oxygen concentration in the liquid elements,

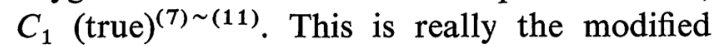
coulometric titration method proposed by the present authors ${ }^{(6)(7)}$.

The same technique was performed in the present study as follows: a uniform very low oxygen potential throughout the liquid cadmium was first established by applying a voltage between wires (1)' and (2)' for a sufficiently long time so that the emf between wires (1) and (2) was set at a preselected value, $E_{1}(m)$. Then, the applied voltage was changed quickly to another value without opening the cell circuit so that the emf between wires (1) and (2) had another value, $E_{2}(m)$, where $E_{2}(m)-E_{1}(m)=$ $500 \mathrm{mV}$. The results showed that the error included in the $C_{1}$ value calculated using eq. (3), attributed to the oxygen released from the solid electrolyte, was lower than $2 \%$. More precise quantity of oxygen released from the solid electrolyte could not be determined because the reference electrode for opencircuit emf measurements had been separated from the one for pump-out experiments. Hence, the $C_{1}$ value calculated using eq. (3) has been adopted in the present study as the $C_{1}$ (true) value.

\section{Correlations and Discussion}

The thermodynamic behavior of oxygen dissolved in liquid elements may be characterized by empirical correlations of the thermodynamic values of oxygen between the various groups of the liquid elements. Recently, we have improved a modified coulometric titration method previously described ${ }^{(7)}$ and obtained the highly precise values for the standard Gibbs energy of solution of oxygen in various liquid elements ${ }^{(8)} \sim(11)$. These uncertainties are within $\pm 5 \mathrm{~kJ} \cdot \mathrm{mol}^{-1}$ in molar enthalpy and $\pm 3 \mathrm{~J} \cdot \mathrm{mol}^{-1} \cdot \mathrm{K}^{-1}$ in molar entropy. Therefore, the correlations, proposed in our previous paper ${ }^{(5)}$, have been established here on the basis of these new data.

Figure 5 shows that plots of the molar enthalpy, $\Delta H^{\circ}$ (in element), versus entropy, $\Delta S^{\circ}$ (in element), of solution of oxygen in liquid elements, for $1 / 2 \mathrm{O}_{2} \quad(101325 \mathrm{~Pa}) \rightarrow \underline{\mathrm{O}}$ $(1 \mathrm{~mol} \%)$, are shifted gradually toward higher values of entropy as the group of the elements is changed from VIb to VIII. When the group of the elements is changed from VIII to Ia, the plot may be shifted toward lower entropy values again. Also, the trend is observed that the partial entropy of oxygen dissolved in a

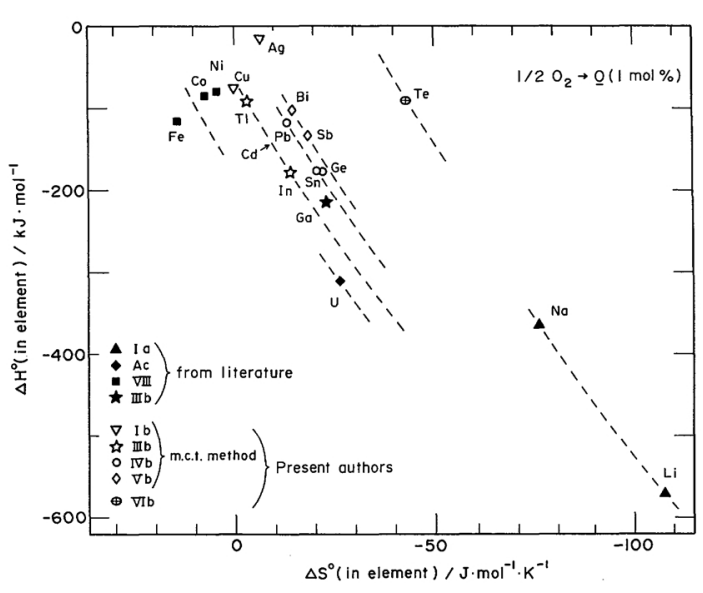

Fig. 5 Correlation between molar enthalpy and entropy of solution of oxygen in liquid elements for $1 / 2 \mathrm{O}_{2}(101325 \mathrm{~Pa}) \rightarrow \underline{\mathrm{O}}(1 \mathrm{~mol} \%)$. The reference state for dissolved oxygen is an infinitely dilute solution. 
particular group of liquid elements decreases along a rough curve with increasing the strength of the metal-oxygen bond. Such a decrease in partial entropy with partial enthalpy has been ascribed to increasing vibrational frequency ${ }^{(1)(3)(5)}$. By considering these trends, the relationship between the molar enthalpy and entropy values, indicated by dashed lines in Fig. 5, was approximately decided for each group of the elements. The line for group IIIb is based on the precise data obtained by the modified coulometric titration method for liquid thallium and indium ${ }^{(9)(10)}$.

As seen from Fig. 5, the plot of copper is very analogous to the curve of the relationship for group IIIb. It is, therefore, predictable that the curve for group IIb must coincides in position with that for group IIIb. Thus, the molar enthalpy and entropy values of solution of oxygen in liquid cadmium were selected to satisfy both eq. (7) and the relationship for group IIIb, indicated by a dashed line in Fig. 5; the result is:

$$
\Delta G^{\circ}(\text { in } \mathrm{Cd}) / \mathrm{J} \cdot \mathrm{mol}^{-1}=-142540+9.4(T / \mathrm{K}) .
$$

By combining eqs. (9) and (10), the saturation solubility of oxygen in liquid cadmium, $C_{s}$ in $\mathrm{mol} \%$, was determined according to eq. (6); the result is:

$$
C_{s}(\text { in Cd }) / \mathrm{mol} \%=\exp \{11.73-14309 /(T / \mathrm{K})\} \text {. }
$$

In Fig. 6, the molar enthalpy of solution of oxygen in liquid elements, for $1 / 2 \mathrm{O}_{2}(101325$ $\mathrm{Pa}) \rightarrow \underline{\mathrm{O}}(1 \mathrm{~mol} \%)$, is shown as a function of the standard enthalpy of formation of their oxides at $298 \mathrm{~K}$ per mol of oxygen, $\Delta H_{298}^{\circ}$ (oxide). Our previous investigation suggested a rough linearity between those values for particular groups of elements ${ }^{(5)}$. The present study has proved that the linear relationship is valid throughout the elements of group $\mathrm{Ib}$ to $\mathrm{VIb}$, except for silver, the slope of which is smaller than unity. It is especially notable in Fig. 6 that the enthalpy value in eq. (10) for oxygen dissolution in liquid cadmium, estimated by using the correlation shown in Fig. 5, is in good agreement with this relationship. The data obtained by the modified coulometric

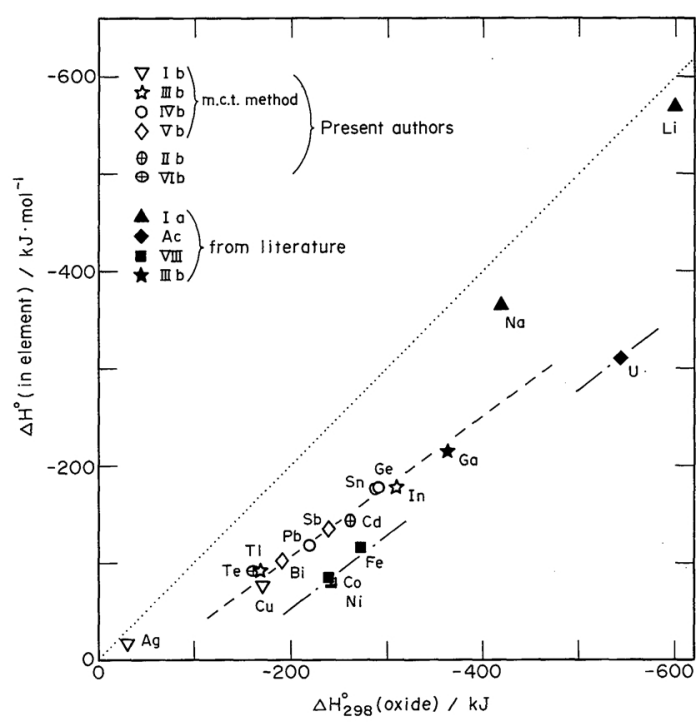

Fig. 6 Molar enthalpy of solution of oxygen in liquid elements as a function of the standard enthalpy of formation of their oxides at $298 \mathrm{~K}$ per mol of $\mathrm{O}$.

titration method, indicated by white points in Fig. 6, are highly reliable, as mentioned before. The least-squares analysis was, therefore, applied only to these highly precise data, and the foregoing linear relationship is expressed by

$$
\begin{aligned}
& \Delta H^{\circ}(\text { in element }) / \mathrm{kJ} \cdot \mathrm{mol}^{-1} \\
& \quad=0.7199 \Delta H_{298}^{\circ}(\text { oxide }) / \mathrm{kJ} \cdot \mathrm{mol}^{-1}+37.19 .
\end{aligned}
$$

The correlation shown in Fig. 5 and eq. (12) must be available to predict the thermodynamic values of oxygen dissolved in liquid elements of group $\mathrm{Ib}$ to $\mathrm{VIb}$, where the data are not available.

The reliable data on the thermodynamic values of oxygen dissolved in liquid zinc, aluminium, silicon, arsenic and selenium are scarce due to experimental difficulty. In the present investigation, these values have been estimated by using the correlations shown in Figs. 5 and 6 . The values of the molar enthalpy of solution of oxygen in the liquid elements were first calculated according to eq. (12) by using the published values of $\Delta H_{298}^{\circ}$ (oxide) ${ }^{(14)(15)}$. The corresponding entropy values were then determined to satisfy the dashed line for each group of the elements in Fig. 5. The calculated results are summarized in Table 1 , where the 


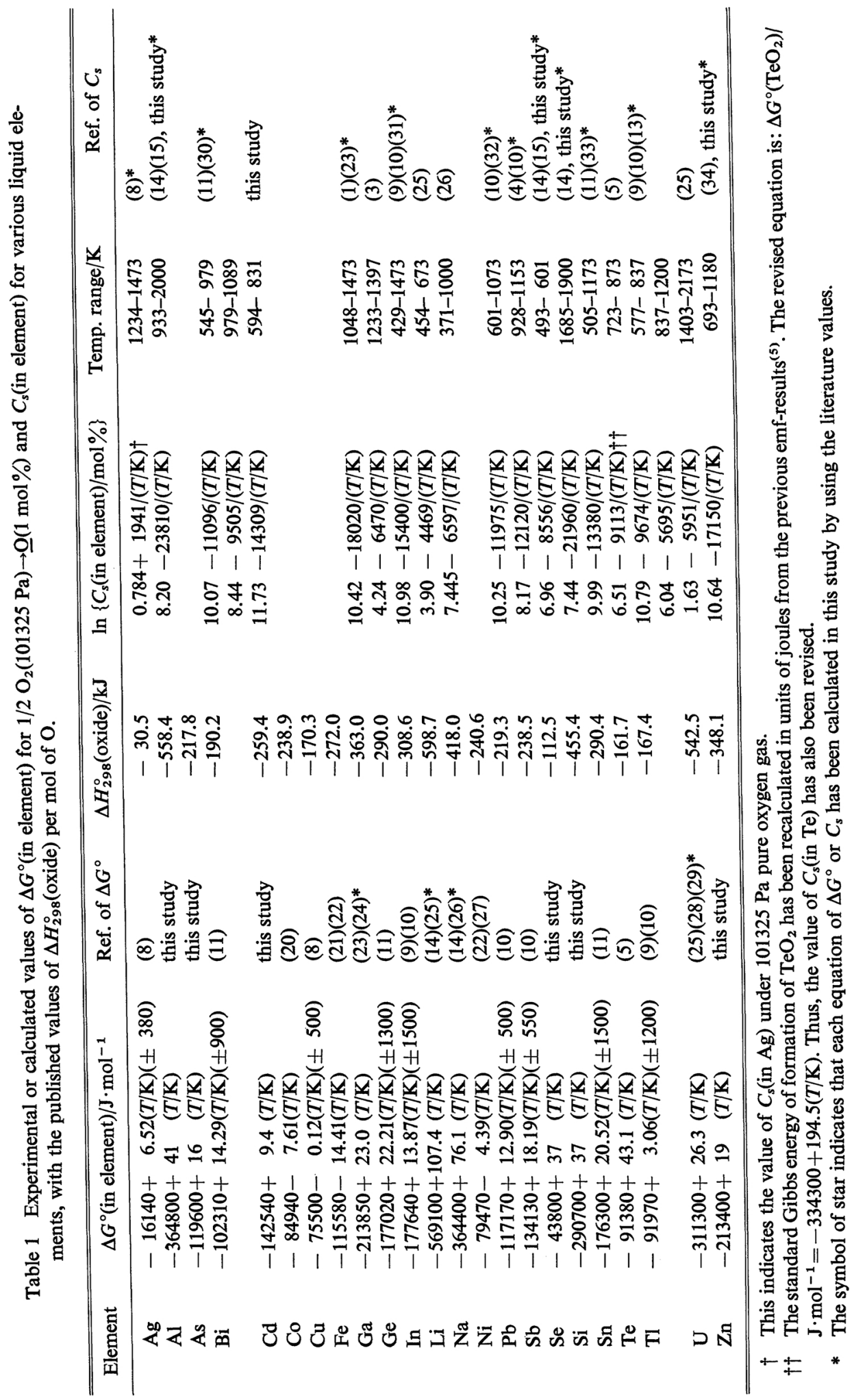


uncertainties in $\Delta G^{\circ}$ (in element) are considered to be within $\pm 15 \mathrm{~kJ} \cdot \mathrm{mol}^{-1}$ for zinc, arsenic and selenium, and within $\pm 30 \mathrm{~kJ}$. $\mathrm{mol}^{-1}$ for aluminium and silicon. One may point out that the melting point of arsenic is higher than its boiling point. Nevertheless, the present calculated results are very useful for predicting the effect of addition of these elements on the activity coefficients of oxygen dissolved in other liquid elements.

In Table 1 , the values of $\Delta G^{\circ}$ (in element) and $\Delta H_{298}^{\circ}$ (oxide), used in Figs. 5 and 6 , are also presented, together with the values of saturation solubility of oxygen in various liquid elements, $C_{s}$ (in element). The reference state for dissolved oxygen is an infinitely dilute solution. All the values of $\Delta H_{298}^{\circ}$ (oxide) shown in Table 1 are based on the compilations of Barin et al. ${ }^{(14)(15)}$

In order to predict the activity coefficient of oxygen in liquid element $B, \gamma_{\underline{Q}(B)}$ from the available value of $\gamma_{\underline{O}(\mathrm{~A})}$ for element $A$, several investigators $^{(17)(18)}$ have used the relationship recommended by Jacob and Alcock ${ }^{(19)}$ :

$$
R T \ln \frac{\gamma_{\mathrm{O}_{(\mathrm{A})}}}{\gamma_{\underline{\mathrm{O}}_{(\mathrm{B})}}}=\Delta H_{298}^{\circ}\left(A_{\mathrm{u}} \mathrm{O}\right)-\Delta H_{298}^{\circ}\left(\mathrm{B}_{\mathrm{v}} \mathrm{O}\right),
$$

where $\Delta H_{298}^{\circ}\left(\mathrm{A}_{\mathrm{u}} \mathrm{O}\right)$ and $\Delta H_{298}^{\circ}\left(\mathrm{B}_{\mathrm{v}} \mathrm{O}\right)$ are the standard enthalpies of formation of oxides of elements A and B at $298 \mathrm{~K}$ per mol of oxygen. We emphasize here that eq. (13) is not based on the experimental results, and the $\gamma_{\underline{Q}_{(B)}}$ value estimated from eq. (13) depends on the kind of the element $\mathrm{A}$ adopted as a reference. For instance, the $\gamma_{\underline{Q}_{(Z n)}}$ values at $773 \mathrm{~K}$, estimated according to eq. (13) on the basis of the published values of $\gamma_{\underline{Q}}(\mathrm{Tl})$ and $\gamma_{\underline{Q}}(\mathrm{Sn}){ }^{(11)}$, are $5.43 \times 10^{-17}$ and $1.82 \times 10^{-13}$, which are significantly inconsistent with each other. On the other hand, our equation of $\Delta G^{\circ}$ (in $\mathrm{Zn})$ shown in Table 1 leads to the $\gamma_{\underline{\mathbf{Q}}_{(\mathrm{Zn})}}$ value at $773 \mathrm{~K}$ of $3.74 \times 10^{-12}$.

As shown in Fig. 6, the slope of the empirical linear relationship between $\Delta H^{\circ}$ (in element) and $\Delta H_{298}^{\circ}$ (oxide) values for the elements of group $\mathrm{Ib}$ to $\mathrm{VIb}$ is smaller than unity. This implies the tendency that the saturation solubility of oxygen in liquid elements is decreased as the $\Delta H_{298}^{\circ}$ (oxide) value is negatively increased. This may be closely related to the tendency that the melting point of the oxide rises generally with increasing strength of the oxygen-element bond.

\section{REFERENCES}

(1) C. B. Alcock and K. T. Jacob: J. Less-Common Metals, 53 (1977), 211.

(2) K. Fitzner and K. T. Jacob: J. Less-Common Metals, 52 (1977), 279.

(3) K. Fitzner, K. T. Jacob and C. B. Alcock: Met. Trans. B, 8B (1977), 669.

(4) K. T. Jacob and P. M. Mathew: Z. Metallk., 70 (1979), 366.

(5) S. Otsuka and Z. Kozuka: Met. Trans. B, 11B (1980), 119.

(6) S. Otsuka and Z. Kozuka: Abst. 8th. ChubuKagaku-Kankeigakukyokai-Shiburengo, Fall Meeting, Nagoya, Japan (Oct. 1977), p. 241-2.

(7) S. Otsuka and Z. Kozuka: Met. Trans. B, 10B (1979), 565.

(8) S. Otsuka and Z. Kozuka: Met. Trans. B, 12B (1981), Sept.

(9) S. Otsuka, T. Sano and Z. Kozuka: Met. Trans. B, $11 B$ (1980), 313.

(10) S. Otsuka and Z. Kozuka: Met. Trans. B, 12B (1981), Sept.

(11) S. Otsuka, T. Sano and Z. Kozuka: Met. Trans. B, 12B (1981), Sept.

(12) K. Kiukkola and C. Wagner: J. Electrochem. Soc., 104 (1957), 379.

(13) S. Otsuka, T. Sano and Z. Kozuka: J. Chem. Therm., 12 (1980), 1115.

(14) I. Barin and O. Knacke: Thermochemical Properties of Inorganic Substances, Verlag Stahleisen m.b.H. Düsseldorf, (1973).

(15) I. Barin, O. Kanacke and O. Kubaschewski: Thermochemical Properties of Inorganic Substances, Suppl., Verlag Stahleisen m.b.H. Düsseldorf, (1977).

(16) S. Otsuka, Y. Matsumura and Z. Kozuka: Proc. Third Interna. Meeting on Solid Electro. Solid State Ion. Galvanic Cells, held in Tokyo, Sept. (1980), in press.

(17) Y. A. Chang and D. C. Hu: Met. Trans. B, 10B (1979), 43.

(18) S. Seetharaman and L.-I. Staffansson: Met. Trans. B, 10B (1979), 539.

(19) K. T. Jacob and C. B. Alcock: Acta Met., 20 (1972), 221.

(20) K. T. Jacob: private communication, Toronto University, March (1979).

(21) T. P. Floridis and J. Chipman: Trans. Met. Soc. AIME, 212 (1958), 549.

(22) T. Chiang and Y. A. Chang: Met. Trans. B, 7B (1976), 453.

(23) L. M. Foster and J. Scardefield: J. Electrochem. Soc., 116 (1969), 494.

(24) I. Katayama, N. Kemori and Z. Kozuka: Trans. Japan Inst. Metals, 16 (1975), 423. 
(25) R. P. Elliott: Constitution of Binary Alloys, McGraw Hill, NY. (1965), p. 584 and 700.

(26) C. B. Alcock and G. P. Stavropoulos: Can. Metall. Quart., 10 (1971), 257.

(27) J. E. Bowers: J. Inst. Metals, 90 (1961-62), 321.

(28) A. E. Martin and R. K. Edwards: J. Phys. Chem., 69 (1965), 1788.

(29) K. Naito and N. Kamegashira: Adv. Nucl. Sci. Technol., 9 (1976), 99.

(30) B. Isecke and J. Osterwald: Z. Phys. Chem.
N.F., 115 (1979), 17.

(31) K. T. Jacob: Trans. Inst. Min. Metall., 87 (1978), C165.

(32) H. Charle and J. Osterwald: Z. Phys. Chem. N.F., 99 (1976), 199.

(33) T. A. Ramanarayanan and A. K. Bar: Met. Trans. B, 9B (1978), 485.

(34) T. C. Wilder: Trans. Met. Soc. AIME, 245 (1969), 1370. 